\title{
Two 1993 Kamchatka Earthquakes
}

\author{
Jean M. Johnson, ${ }^{1}$ Yuichiro Tanioka, ${ }^{1}$ Kenji Satake, ${ }^{1}$ and Larry J. RufF ${ }^{1}$
}

\begin{abstract}
Two earthquakes occurred in 1993 off southern Kamchatka. They have similar surface wave magnitudes, focal mechanisms, and depths, but have distinctly different characteristics. The November earthquake is a standard or "impulsive" $M 7$ underthrusting event. The June earthquake is a tsunamigenic or "low-stress-drop" event with several unusual characteristics, including a large, diffuse aftershock zone, directivity, and a long source time function. The 1993 earthquakes ruptured a segment of the Kamchatka Arc which has not ruptured since 1904. The 1993 earthquakes seem to signal the midpoint in the southern Kamchatka seismic cycle.
\end{abstract}

Key words: Earthquake parameters, tsunamis, earthquake cycle.

\section{Introduction}

In 1993, two $M \sim 7$ earthquakes occurred immediately adjacent to each other off the east coast of southern Kamchatka. The first occurred on 8 June $\left(51.218^{\circ} \mathrm{N}\right.$, $\left.157.829^{\circ} \mathrm{E}, 13: 03 \mathrm{GMT}, M_{s}=7.2\right)$ the second on 13 November $\left(51.934^{\circ} \mathrm{N}\right.$, $\left.158.647^{\circ} \mathrm{E}, 1: 18 \mathrm{GMT}, M_{s}=7.1\right)$. The focal mechanisms of the two earthquakes (Figure 1) are similar and suggest that these are typical underthrusting events occurring at the down-dip edge of the coupled plate interface, which in this region is $38-40 \mathrm{~km}$ deep (TichelaAR and RUfF, 1993). While the November event is in every respect a standard event of its kind, the June earthquake has certain unusual characteristics. First, this event produced anomalous aftershock activity, far up dip of the main shock epicenter. Second, the seismic moment of the earthquake as determined by CMT inversion is larger than expected from the surface wave magnitude. Third, and most importantly, the June earthquake generated a tsunami that was observed on the east coast of Kamchatka and on tide gauges on several Pacific islands. The waveforms recorded at the IRIS Pasadena station (Figure 2) show the different characters of the two events, in particular, the long period nature of the waves from the June event.

\footnotetext{
${ }^{1}$ Department of Geological Sciences, University of Michigan, Ann Arbor, MI 48109-1063, U.S.A.
} 


\section{Kamchatka Earthquakes}

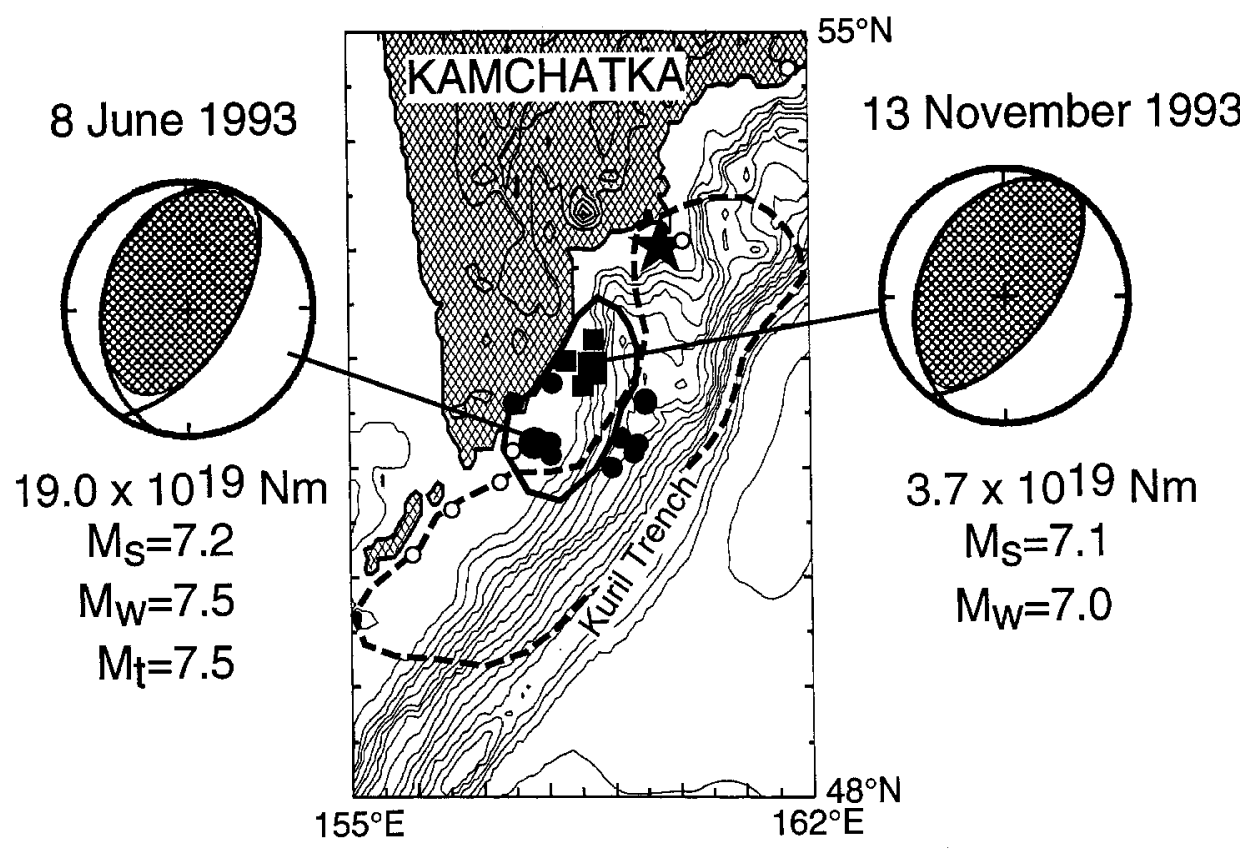

Figure 1

Aftershock zones of Kamchatka earthquakes. One-month aftershocks of the June 1993 earthquake are solid circles, solid squares are aftershocks of the November 1993 earthquake. Data are from NEIC. The dashed line outlines the aftershock zone of the 1952 earthquake, the large star is the epicenter (KelleHer and SAviNo, 1975), the solid line outlines the inferred aftershock zones of the 1904 earthquakes (FEDOTOV et al., 1982). Open circles are epicenters of earthquakes defining the down-dip edge of the coupled plate interface (TICHELAAR and RUFF, 1993).

We analyzed both the June and November earthquakes using several seismological methods. We determined the best focal mechanism, depth, and source time function for each. We also analyzed the tsunami of the June event in an attempt to determine the generating mechanism. The results suggest that the June Kamchatka earthquake may be an example of a low-stress-drop earthquake.

This portion of the Kuril-Kamchatka Arc last ruptured in the great 1952 Kamchatka earthquake (4 November $1952,52.75^{\circ} \mathrm{N}, 159.5^{\circ} \mathrm{E}, M_{w}=9.0$ ). The 1952 zone, however, did not rupture at depth in the area of the 1993 earthquakes. This part of the plate interface last ruptured in a series of three earthquakes in June 1904. These three earthquakes were all of similar magnitude, approximately $M_{s}=7.2$ (PACHECO and SYKES, 1992). This makes them directly comparable to the 1993 events. The relationship between all these events is sketched in Figure 1. We discuss the relationship of the 1993 earthquakes to both the 1904 earthquakes and 
Broadband waveforms recorded at IRIS station in Pasadena, CA

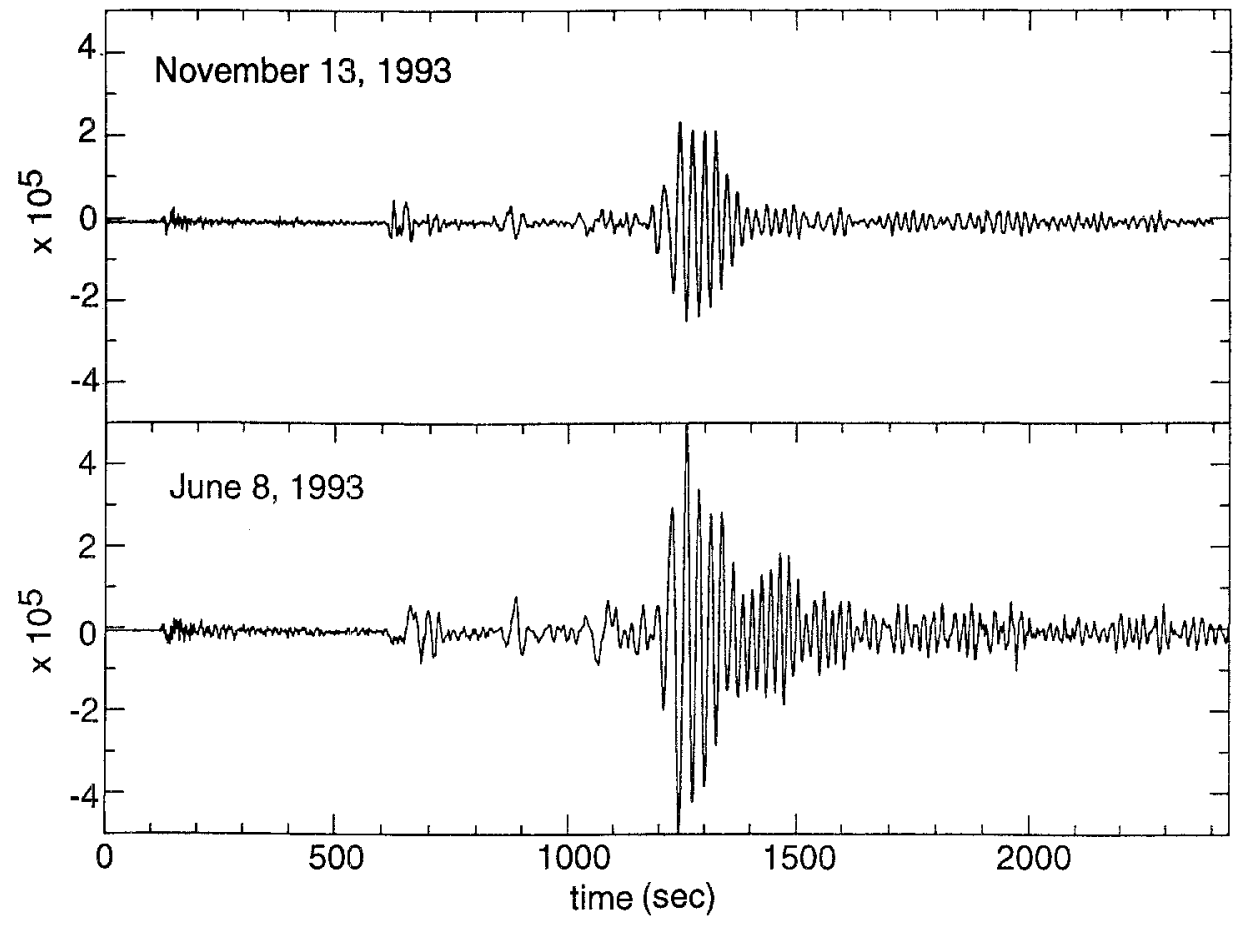

Figure 2

Broadband waveforms recorded at the IRIS network station in Pasadena, CA for the June and November 1993 Kamchatka earthquakes. The time axis is seconds after the beginning of the record.

the great 1952 Kamchatka earthquake. We also attempt to discern the basic features of the seismic cycle in this portion of the Kamchatka Arc.

\section{Seismic Data Analysis}

We performed CMT inversion (DzIEWONSKI et al., 1981) for both events, using ten stations of the IRIS network for the June event and eight stations for the November event. The focal mechanism and seismic moment can be seen in Figure 3. The Harvard CMT (DzIEWONSKI et al., 1981) and U.S.G.S. (SIPKIN, 1986) focal mechanisms are also shown for comparison and are listed in Table 1. The strike, dip, and rake of the presumed fault plane for the June earthquake are $191^{\circ}, 27^{\circ}$, and $66^{\circ}$. For the November event, they are $204^{\circ}, 31^{\circ}$, and $77^{\circ}$. These fault planes are consistent with the direction of subduction in the Kuril-Kamchatka trench. The seismic moment of the November event, $3 \times 10^{19} \mathrm{Nm}$, or $M_{w}=7.0$, is compatible with the surface wave magnitude of 7.1 . The moment of the June event, 


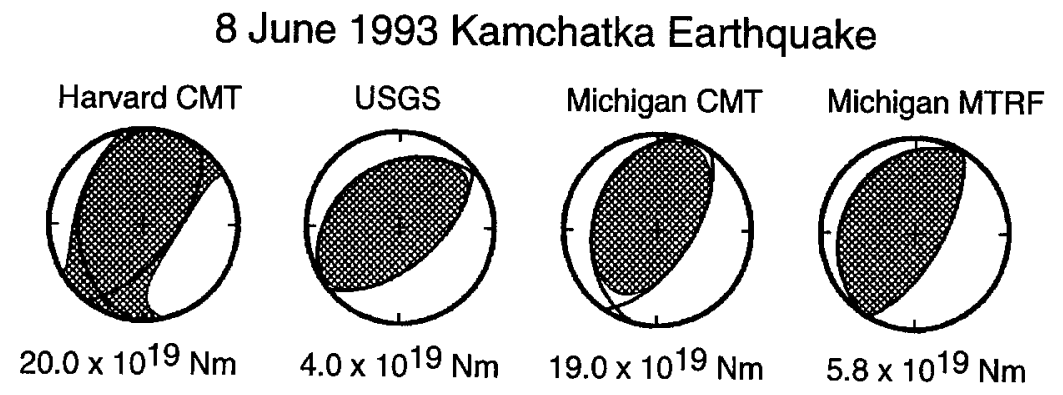

13 November 1993 Kamchatka Earthquake

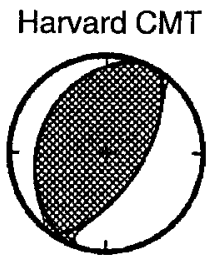

$3.9 \times 10^{19} \mathrm{Nm}$

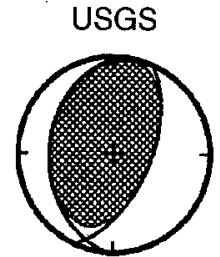

$2.9 \times 10^{19} \mathrm{Nm}$

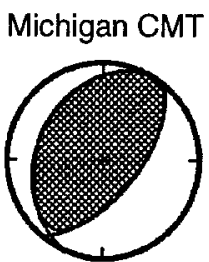

$3.7 \times 10^{19} \mathrm{Nm}$
Michigan MTRF

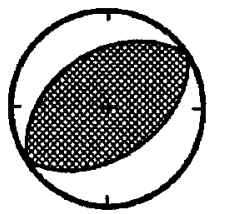

$1.7 \times 10^{19} \mathrm{Nm}$

Figure 3

Focal mechanisms and seismic moments of the 1993 earthquakes.

$19.0 \times 10^{19} \mathrm{Nm}$, however, is over five times greater than the November earthquake. The moment magnitude of the June earthquake is 7.5 , higher than the surface wave magnitude of 7.2 .

We also performed body wave inversion for the moment tensor rate functions (MTRF) (RUFF and Miller, 1994) to determine the best depth and focal mechanism for both earthquakes (see Figures 3 and 4). The strike, dip, and rake of the June earthquake are $212^{\circ}, 24^{\circ}$, and $92^{\circ}$; for the November earthquake, $236^{\circ}$, $42^{\circ}$, and $90^{\circ}$. To determine the best depth, we searched over a range of possible depths to find the highest correlation coefficient, which measures the fit of the synthetics to the observed waveforms. The best depth of the June event is $40 \mathrm{~km}$, which is significantly shallower than the NEIC published depth of $70 \mathrm{~km}$. The best depth of the November event is more equivocal, but the highest correlation occurs at $45 \mathrm{~km}$. The correlation declines significantly below $50 \mathrm{~km}$ for both events. This places both events at the down-dip edge of the coupled plate interface and certainly not deeper. As seen in Figure 1, both events lie along a line of earthquakes which have occurred in the past thirty years which define the edge of the coupled plate interface (TICHELAAR and RUFF, 1993). It is interesting to note that there is a definite gap in moderate size earthquakes at the southern edge of the Kamchatka Arc which the 1993 events filled. 
Table 1

Location and focal mechanisms of 1993 earthquakes and principal aftershocks

\begin{tabular}{lrcccc}
\hline \multicolumn{1}{c}{ Date } & Location & Strike & Dip & Rake & $\begin{array}{c}\text { Moment } \\
\times 10^{19} \mathrm{Nm}\end{array}$ \\
\hline $\begin{array}{l}\text { 8 June } \\
13: 03: 36.48\end{array}$ & $\begin{array}{r}51.24^{\circ} \mathrm{N} \\
157.80^{\circ} \mathrm{E}\end{array}$ & 207 & 29 & 79 & 20 \\
$\begin{array}{l}M_{s}=7.2 \\
\text { 10 June }\end{array}$ & $51.170^{\circ} \mathrm{N}$ & 205 & 32 & 69 & 0.014 \\
$12: 04: 56.41$ & $159.097^{\circ} \mathrm{E}$ & & & & \\
$m_{b}=5.5$ & & & & & \\
$10 \mathrm{June}$ & $51.115^{\circ} \mathrm{N}$ & 206 & 35 & 71 & 0.014 \\
$12: 58: 59.49$ & $159.272^{\circ} \mathrm{E}$ & & & & \\
$m_{b}=5.8$ & & & & & \\
12 June & $51.259^{\circ} \mathrm{N}$ & 214 & 32 & 92 & 0.27 \\
$20: 33: 25.70$ & $157.692^{\circ} \mathrm{E}$ & & & & \\
$m_{b}=5.9$ & & & & & \\
13 November & $51.952^{\circ} \mathrm{N}$ & 206 & 31 & 83 & 3.9 \\
$01: 18: 04.18$ & $158.796^{\circ} \mathrm{E}$ & & & & \\
$M_{s}=7.1$ & & & & & \\
17 November & $51.81^{\circ} \mathrm{N}$ & 208 & 36 & 73 & 0.12 \\
$11: 18: 51.62$ & $158.659^{\circ} \mathrm{E}$ & & & & \\
$m_{b}=6.1$ & & & & & \\
\hline
\end{tabular}

In addition to finding the best depth, we also determined the source time function of each earthquake. The source time function for the November earthquake (Figure 5) consists of a single pulse of moment release of about $10 \mathrm{sec}$ duration. This is typical of many $M 7$ earthquakes which occur in subduction zones (SCHWARTZ and RUFF, 1987). On the other hand, the source time function of the June event has a duration of approximately $30 \mathrm{sec}$. This long duration of moment release is of special interest when the aftershock activity and the tsunami are considered. Further discussion relating to this point can be found below in the section dealing with tsunami data analysis.

In attempting to determine the source time function for the June earthquake, we discovered that it was quite difficult to fit all the data using a single source time function. This led us to consider whether there was any directivity affecting the data. We divided the stations used in the body wave inversion into several groups based on their azimuthal distribution. We then inverted the waveforms from each group. The results are shown in Figure 6. In general, the stations to the east of the earthquake have a compressed source time function of approximately $20 \mathrm{sec}$, while those to the west exhibit a lengthened source time function of about $30 \mathrm{sec}$. This indicates that the rupture propagated from west to east, or that rupture initiated at 


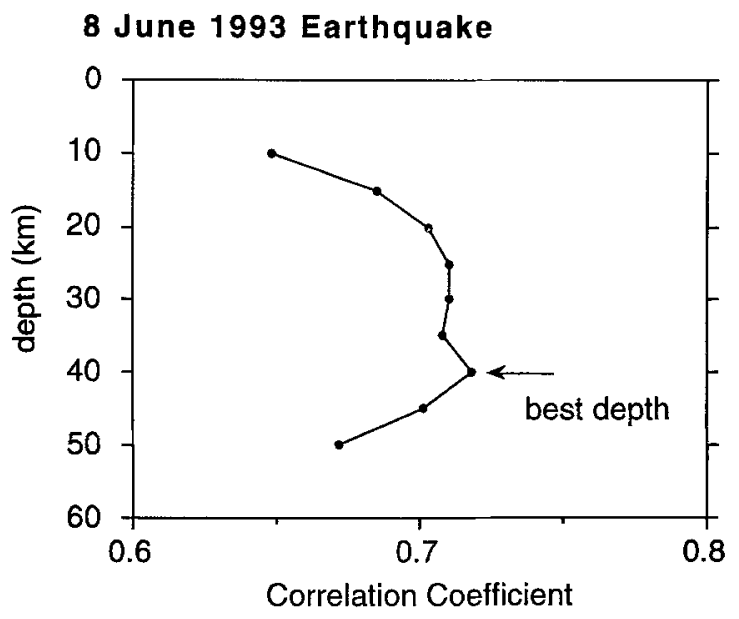

13 November 1993 Earthquake

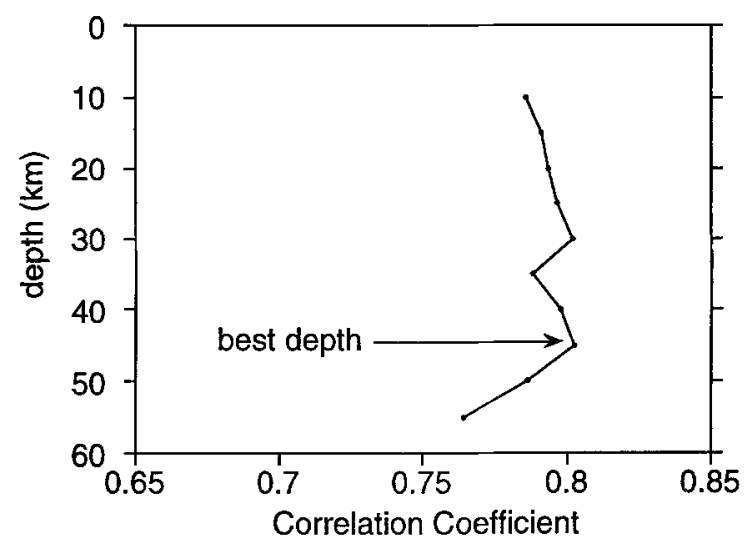

Figure 4

Correlation coefficient measuring the fit between the observed and synthetic as a function of depth.

the down-dip edge of the plate interface and proceeded updip. From the individual groups of source time functions, we estimate the length of faulting by using the variation in timing of the truncation of the source time functions relative to the onset. The observed delay time $T_{i}$ at the $i$ th station relative to the epicentral arrival time $T_{0}$ is

$$
T_{i}-T_{0}=X\left(\frac{1}{v_{r}}-p \cos \theta\right)
$$

where $X$ is the distance to the termination of faulting, $v_{r}$ is the rupture velocity, $p$ is the ray parameter, and $\theta$ is the angle between the rupture azimuth and the station azimuth. A full discussion of directivity analysis can be found in BECK and RUFF (1984). To simply estimate the length of faulting, we assume the rupture velocity is 


\section{Source time functions of Kamchatka Earthquakes}

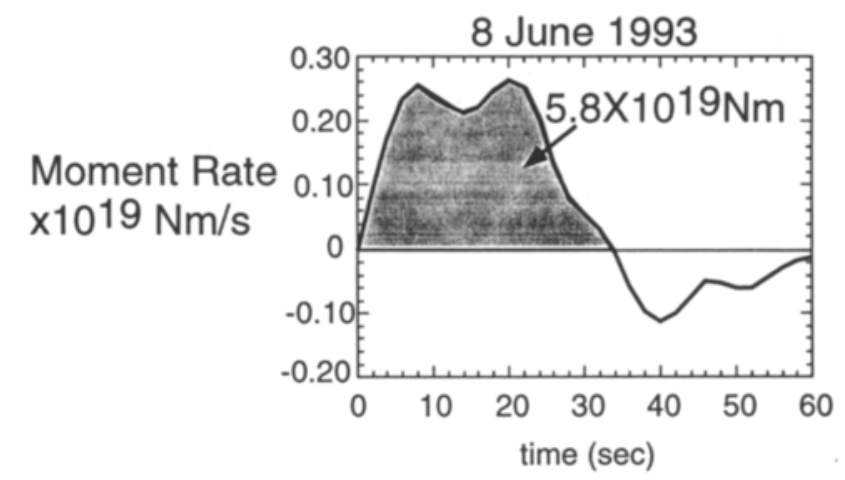

13 November 1993

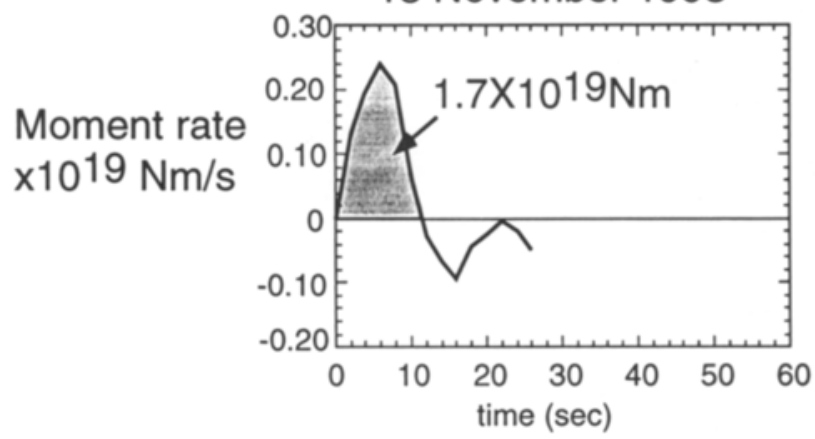

Figure 5

Source time functions of 1993 Kamchatka earthquakes from inversion of $P$ waves.

$3.0 \mathrm{~km} / \mathrm{sec}$ and the rupture azimuth is perpendicular to the fault strike. A time delay of approximately 10 seconds produces a fault length of about $100 \mathrm{~km}$, which is consistent with the aftershock zone.

To complete our study of the seismic data for both earthquakes, we analyzed the aftershocks. The focal mechanisms of the larger aftershocks are listed in Table 1. They are similar to the focal mechanisms of the main shocks. As seen in Figure 1, however, the aftershock distributions of the June and November earthquakes are quite different. The aftershocks of the November event are clustered close to the main shock. The aftershocks of the June event are spatially more diffuse. Also, there is a significant cluster of aftershocks to the east of the main shock. Considering the unusually long duration of the source time function, as described above, and the length of faulting as estimated by the directivity, this distribution is not surprising. The differences between the two aftershock zones will be discussed in more detail later. 


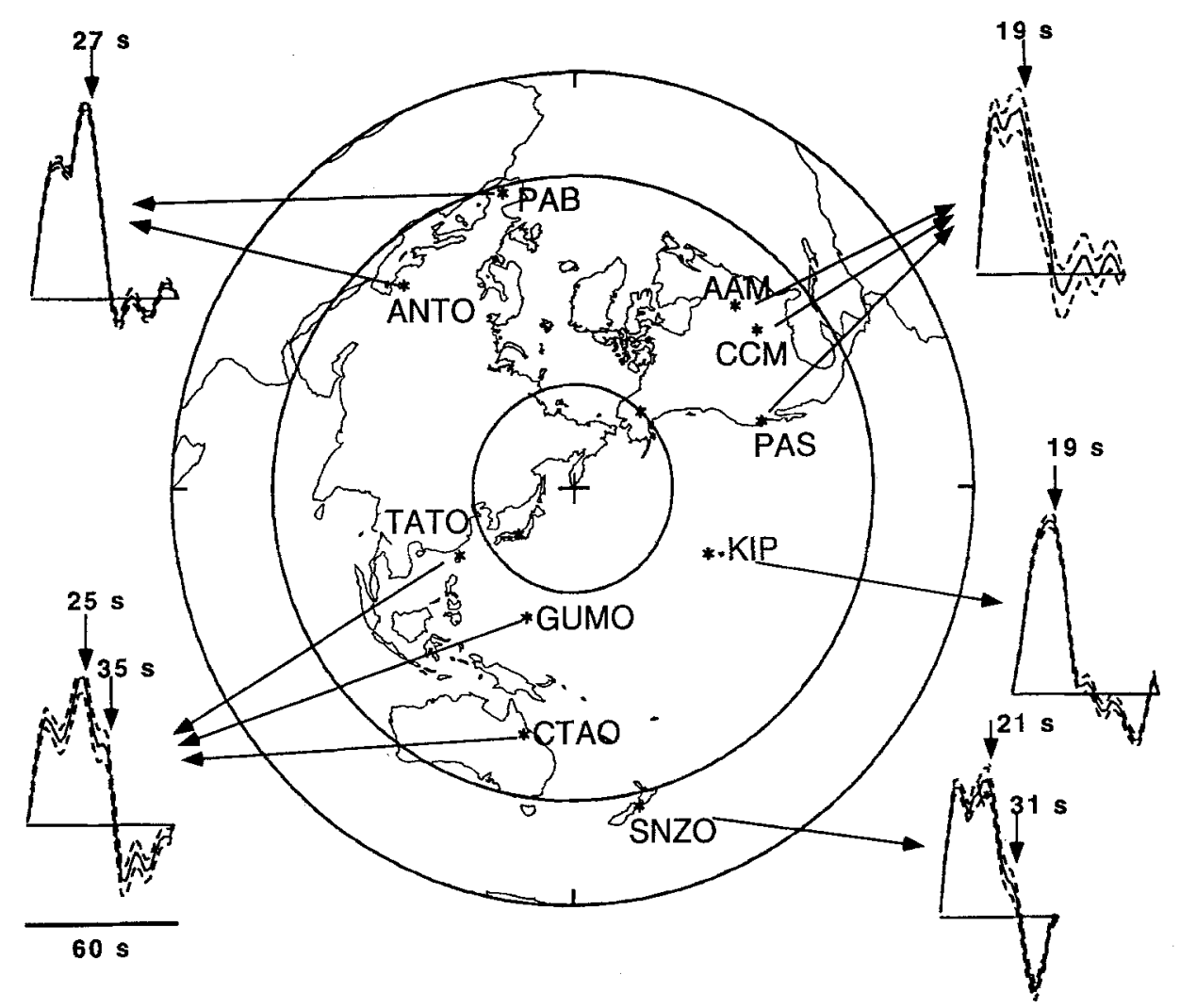

Figure 6

Directivity results. Arrows indicate the stations used in the inversion for each of the source time functions. The cross indicates the epicenter of the June 1993 earthquake.

In summary, the June and November earthquakes are distinctly different, despite the similarity in focal mechanism, depth, and surface wave magnitude. The November earthquake is a standard underthrusting earthquake such as commonly occurs at the down-dip edge of the coupled plate interface. The June event is more unusual, but the seismic data are all consistent with a longer duration of faulting on a longer fault.

\section{Tsunami Data Analysis}

One of the most interesting aspects of the June event was the tsunami it generated. It was observed on Kamchatka $(10 \mathrm{~cm}$ at Petropavlosk-Kamchatshiy, V. $\mathrm{K}$. Gusiakov, written communication) and was also recorded on tide gauges at 


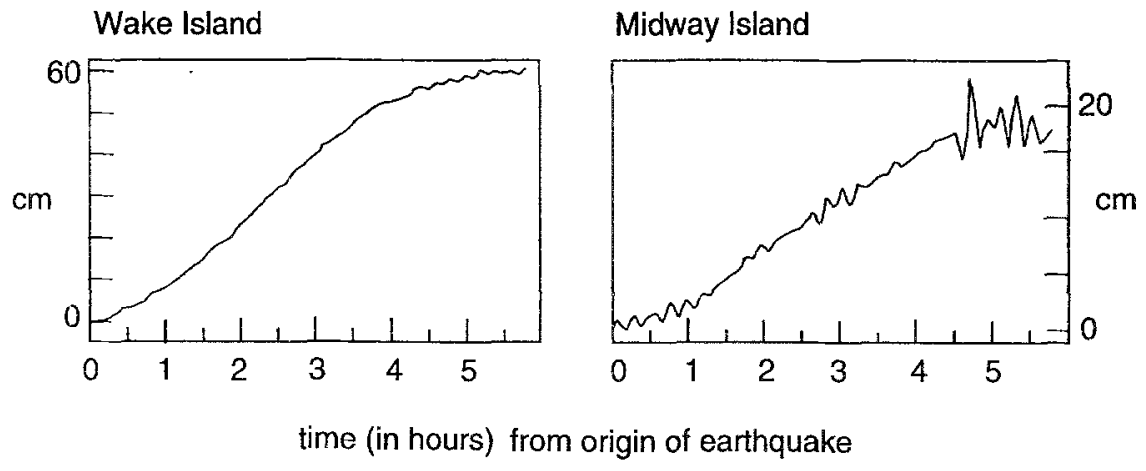

Figure 7

Digitized marigrams of the June 1993 tsunami recorded at Wake and Midway.

Midway $(8 \mathrm{~cm})$, Wake $(5 \mathrm{~cm})$, Hawaii $(12 \mathrm{~cm})$, and Shemya $(10 \mathrm{~cm})$ in the Aleutians. The tsunami magnitude (ABE, 1979) as determined by the maximum height of the tsunami on tide gauge records is 7.5. This is higher than the surface wave magnitude of 7.2. While it is not a tsunami earthquake as defined by ABE (1979), the discrepancy between the surface wave magnitude and the tsunami magnitude does point out the interesting character of this event. Luckily, several tsunami waveforms are available for this earthquake (Figure 7); unfortunately, the sampling rate is only once every six minutes, making the records of limited use. One of them, however, from Midway, can be used to constrain the tsunami generation mechanism.

In constructing models for the tsunami generation, we attempted to remain within the constraints imposed by the seismic data. Thus, for each model, the seismic moment is held constant. This determines the slip on each fault. Also, we attempted to choose faulting parameters consistent with the focal mechanism determined by the CMT inversion. The four models are shown in Figure 8.

In the first model, we assume the moment is released uniformly along the entire aftershock zone. The fault is $110 \mathrm{~km}$ downdip $\times 50 \mathrm{~km}$ along strike; the depth to the top edge of the fault is $18 \mathrm{~km}$, the dip is $13^{\circ}$, and the slip amount is $90 \mathrm{~cm}$ of dip-slip motion. Although the focal mechanism shows that the dip of the fault plane is $25-30^{\circ}$, the subduction of the Pacific Plate occurs at a dip of $13^{\circ}$ (TichelaAR and RUFF, 1993); therefore, we chose the $13^{\circ}$ value as the dip to be consistent with the actual plate geometry.

In the second model, we assume that faulting continued all the way to the trench. This is possible if we consider the maximum directivity time delay allowed by the seismic data. If it is $16 \mathrm{sec}$, rather than $10 \mathrm{sec}$, then rupture could have propagated to the trench. Although there are no aftershocks near the trench, this is not unusual, as the trench is filled with soft sediments unlikely to sustain large aftershocks. The fault for this model is $165 \mathrm{~km}$ downdip $\times 50 \mathrm{~km}$ along strike, the 


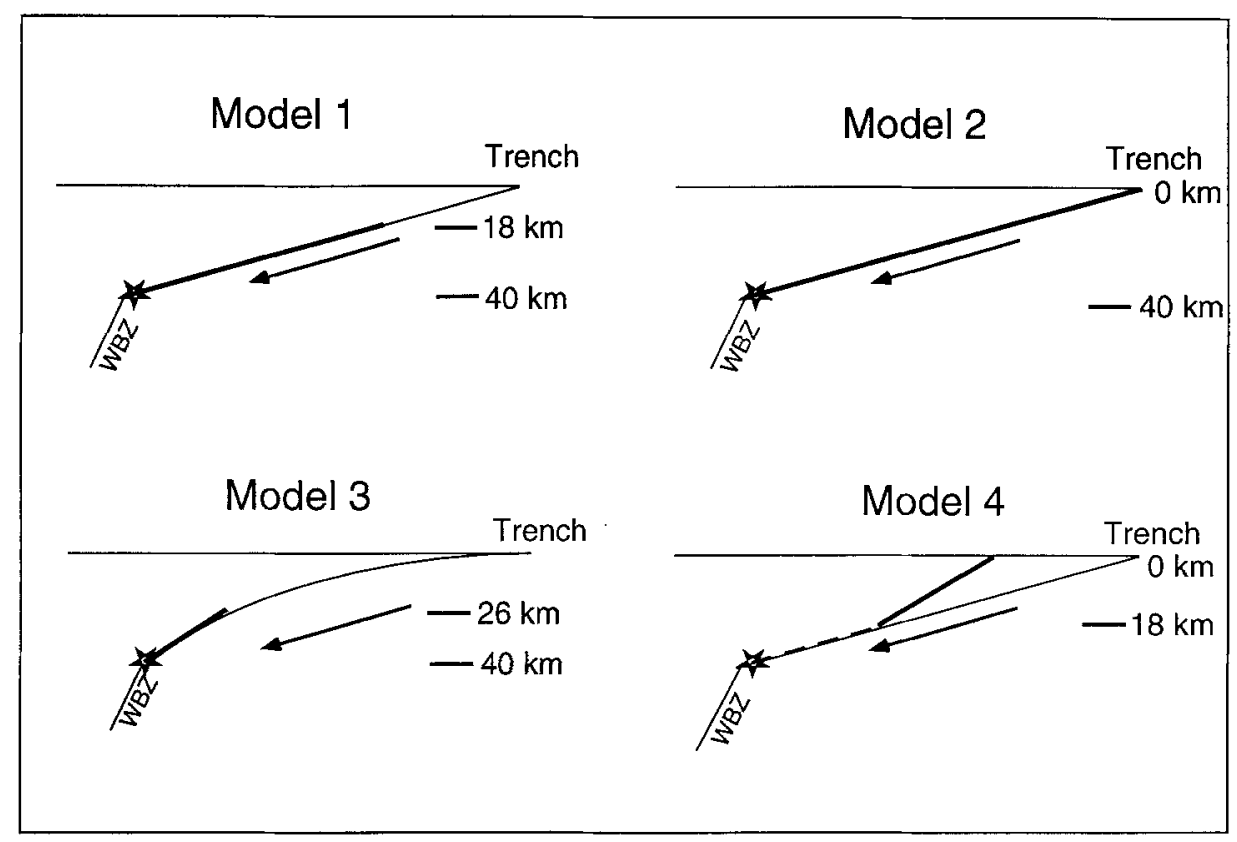

Figure 8

Models used to determine the initial condition of the June tsunami.

depth to the top of the fault is $0.5 \mathrm{~km}$, the dip is $13^{\circ}$, and the slip amount is $60 \mathrm{~cm}$ dip-slip.

In the third model, we assumed that all the moment release occurred in the deep section of the aftershock zone and that no moment was released in the area of the second cluster of aftershocks. The fault parameters are: $50 \mathrm{~km}$ length along strike, $35 \mathrm{~km}$ width down-dip, depth to top of faulting $26 \mathrm{~km}$, dip $30^{\circ}$, and slip amount $290 \mathrm{~cm}$. The dip is consistent with the focal mechanism.

In the fourth model, we allow all the moment to be released on a subsidiary fault in the overlying plate. This corresponds to the cluster of aftershocks which are located to the east of the main shock. The faults parameter are: length $50 \mathrm{~km}$, width $50 \mathrm{~km}$, and slip $200 \mathrm{~cm}$. We chose the dip to be $30^{\circ}$ to be consistent with the focal mechanism. The faulting was allowed to reach the surface.

Using each of these fault models, we computed the ocean-bottom deformation applying the equations of OKADA (1985) for an elastic half-space. Using this as the initial condition for the tsunami, we calculated the tsunami propagation as a linear-long wave by a finite-difference method using the actual bathymetry of the Pacific Ocean. In the source area and in the northern Pacific, we used $5^{\prime} \times 5^{\prime}$ grid size. In the area around Midway, however, we used a grid size of $1^{\prime} \times 1^{\prime}$ to ensure the accuracy of the synthetic waveform. 


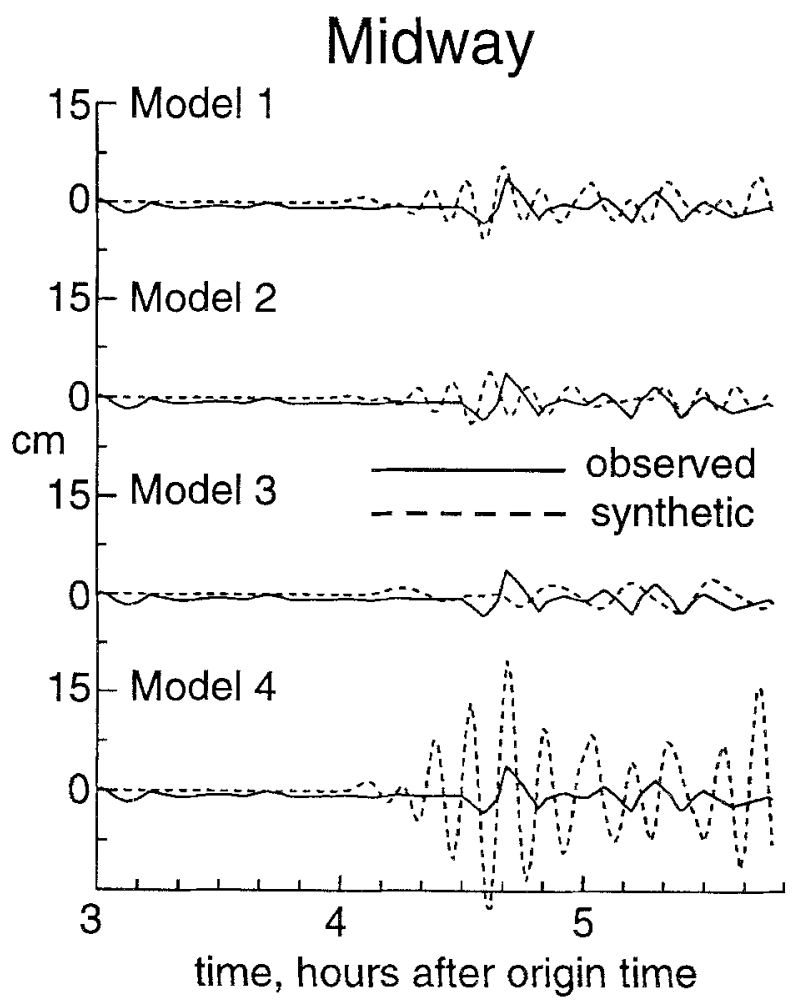

Figure 9

Observed and synthetic tsunami waveforms.

Figure 9 shows the results of forward modeling. The observed waveform is compared to the synthetic for each model. It is immediately obvious that none of the models matches the observed waveform perfectly. Both Model 1 and Model 2 have approximately the correct amplitude. The largest pulse of Model 2 arrives too early, as would be expected, as the slip is allowed to go to the trench. The arrival time of each of the synthetics does not match the observed first pulse, but this could be due to the aliasing caused by the undersampling. The amplitude of Model 3 is too small to match the observed, and the amplitude of Model 4 is too large.

It is not possible to uniquely determine the tsunami generation mechanism from a single tide gauge record. We can only make a qualitative estimate of the tsunami source. Of the four models we used, Models 3 and 4 are ruled out, but the problem of aliasing in the original tide gauge record makes it difficult to make an absolute determination between Models 1 and 2. Model 1, however, is slightly preferable as it agrees more closely on the whole with the seismic data. Unfortunately, nothing more can be determined from the tsunami data analysis. 


\section{Low-stress-drop earthquakes}

Perhaps more interesting than the mechanism of faulting resulting in a tsunami, is the question of why the June earthquake is so different from the adjacent November earthquake. One possible answer can be suggested by looking at other well-studied earthquakes in the Kuril Trench. The work of SCHWARTZ and RUFF (1987), which examines large earthquakes $(M \geq 7.0)$ in the southern Kuril Trench, offers some explanation for these types of events.

There were several earthquakes in the southern Kurils similar to the June 1993 Kamchatka earthquake. These events had large aftershock areas which extended to the trench, they generated tsunamis, and they had unusually long source time functions. SCHWARTZ and RUFF refer to these as "low-stress-drop" events. Other earthquakes in the Kurils were similar to the November 1993 Kamchatka earthquake. They occurred at the down-dip edge of the coupled plate interface, their aftershocks were tightly clustered near the main shock, and their source time functions were of short duration. These events are referred to as "impulsive" events. There is even one instance of a pair of adjacent earthquakes in the Kurils that exhibits the opposing characteristics seen in the Kamchatka earthquakes. The first earthquake (21 December $1946, M_{s}=7.2,44.1^{\circ} \mathrm{N}, 148.2^{\circ} \mathrm{E}$ ) had an unusually large aftershock zone, much like the June 1993 event. Though this 1946 Kuril earthquake did not generate a tsunami (or at least none is reported) it appears to be one of the low-stress-drop earthquakes. Immediately adjacent to this event, an impulsive earthquake occurred four months later ( 14 April $1947, M_{s}=7.0,44.0^{\circ} \mathrm{N}, 148.5^{\circ} \mathrm{E}$ ), similar to the November 1993 Kamchatka event.

To determine if the June event is a low-stress-drop earthquake, we estimate the stress drop from the seismic moment determined by the MTRF inversion $m$ and the duration of the source time function $2 \tau$ (YoshidA et al., 1992). We use the moment determined by the body wave inversion, $5.8 \times 10^{19} \mathrm{Nm}$, and the half duration of the time function, $15 \mathrm{sec}$. The stress drop is estimated as $\Delta \sigma=2.5 \mathrm{~m} /\left(v_{r} \tau\right)^{3}$, where $v_{r}$ is the rupture velocity. We assume the rupture velocity is $3.0 \mathrm{~km} / \mathrm{s}$. The stress drop we estimate is 16 bars. We also estimate the stress drop of the November event to be 125 bars, where $m=1.8 \times 10^{19} \mathrm{Nm}$ and $\tau=5 \mathrm{sec}$. This confirms the different character of the two events and lends credence to the supposition that the June event is a "low-stress-drop" earthquake and the November earthquake is an "impulsive" event.

As the parallels we have have already drawn between the southern Kuril Arc and the Kamchatka Arc have proven valid, we can perhaps proceed further and speculate on the controlling factors for these types of events. SCHWARTZ and RUFF showed that the locations of the low-stress-drop and impulsive events were controlled by the asperities which ruptured in large or great earthquakes. The smaller events are generally adjacent to the asperities. If the 1993 earthquakes are also controlled by the asperities in the Kamchatka region, we can hypothesize on the 
location of at least one asperity of the 1952 great earthquake. Assuming that an asperity is associated with the location of the epicenter, we can fix one asperity to the northeast of the 1993 earthquakes. Unfortunately, this can only be speculation at present because the slip distribution of the 1952 earthquake is unknown. Hopefully, in the future, tsunami waveform inversion can be performed, such as has been done for the 1957 Aleutian earthquake (JOHNSON and SATAKE, 1993), which will allow us to test our hypothesis.

\section{Discussion}

As noted in the introduction, the two 1993 Kamchatka earthquakes occurred within the rupture area of three earthquakes which occurred in 1904. Little is known about these events; only their magnitudes are known, being estimated as $M_{s}=7.1-7.3$ (PACHECO and SYKeS, 1992). The rupture area of the 1904 events, while not well determined, apparently did not rupture in the great 1952 Kamchatka earthquake which has a moment magnitude of $M_{w^{\prime}}=9.0$ (KANAMORI, 1977). The aftershock zone of the 1952 earthquake (KelleHER and SAvino,1975; Fedotov et al., 1982) wraps around the 1904/1993 rupture areas with little overlap between the two.

The historical seismicity of the 1993 rupture zone does predate 1904 . The 1952 zone, on the other hand, has a longer history. Tsunami evidence suggests that the 1952 area ruptured previously in $M 9$ earthquakes in 1737 (IDA et al., 1967) and in 1841 (ABE, 1979). If the rupture zones for each of these earthquakes correspond, as the evidence suggests, to the 1952 zone, then this segment of the arc has a fairly regular recurrence history with an interval of about 108 years.

There are several different possible scenarios which could define the rupture cycle in this region. The first is that the southern Kamchatka Arc is one integrated, complex system with interacting parts: the 1952 zone and the 1993 zone. Each part ruptures approximately every 100 years, but out of phase by one-half cycle, as appears from the 1841-1904-1952-1993 sequence. Another possibility is that the two systems are essentially independent of each other. This is slightly difficult to explain as the 1904/1993 zone is down-dip of the larger event and is almost encompassed by it. It seems likely that the larger system must have some effect on the down-dip system. On the other hand, this may explain the difference in rupture styles; that is, the 1904/1993 zone appears to rupture in a series of $M 7$ earthquakes while the 1952 zone ruptures in a single great event. A final possibility is that the 1904/1993 zone ruptures about every 50-60 years and was a part of the 1737 and 1841 zones. Why the 1904/1993 zone apparently did not rupture in 1952 remains unexplained.

It is impossible to determine if the 1904/1993 rupture area was involved in the 1737 or 1841 earthquakes, but the 1841-1904-1952-1993 sequence does suggest an 
interesting rupture cycle in this region. The 1904 earthquakes occurred 63 years after the 1841 earthquake and 48 years before the 1952 earthquake. The 1993 earthquakes occurred 41 years after the 1952 earthquake. The 1904/1993 zone seems to be rupturing at approximately the midpoint of the 1952 cycle. The 1993 earthquakes could be considered a "flag" that the entire system is continuing to operate as it has in the last seismic cycle.

\section{Conclusions}

The 1993 Kamchatka earthquakes, while having similar surface wave magnitudes, focal mechanisms, and depths, have distinctly different characteristics. The November earthquake is a standard or "impulsive" $M 7$ underthrusting event. The June earthquake is a tsunamigenic or "low-stress-drop" event with several unusual characteristics. The 1993 earthquakes ruptured a segment of the Kamchatka Arc which has not ruptured since 1904. The 1993 earthquakes seem to signal the midpoint in the southern Kamchatka seismic cycle.

\section{Acknowledgements}

This work was supported by the National Science Foundation (EAR91-17800 and EAR90-19003).

\section{REFERENCES}

ABe, K. (1979), Size of Great Earthquakes of 1873-1974 Inferred from Tsunami Data, J. Geophys. Res. $84,1561-1568$.

BECK, S., and RufF, L. (1984), The Rupture Process of the Great 1979 Colombia Earthquake: Evidence for the Asperity Model, J. Geophys. Res. 89, 9281-9291.

Dziewonski, A. M., Chou, T. A., and Woodhouse, J. H. (1981), Determination of Earthquake Source Parameters from Waveform Data for Studies of Global and Regional Seismicity, J. Geophys. Res. 86, $2825-2853$.

Fedotov, S. A., Chernyshev, S. D., and Chernysheva, G. V. (1982), The Improved Determination of the Source Boundaries for Earthquakes of $M \geq 7.75$, of the Properties of the Seismic Cycle, and of Long-term Seismic Prediciton for the Kurile-Kamchatka Arc, Earthq. Predict. Res. 1, 153-171.

Iida, K., Cox, D. C., and Pararas-Carayannis, G. (1967), Preliminary Catalogue of Tsunamis Occurring in the Pacific Area, Hawaii Institute of Geophysics, University of Hawaii.

Johnson, J. M., and Satake, K. (1993), Source Parameter of the 1957 Aleutian Earthquake from Tsunami Waveforms, Geophys. Res. Lett. 20, 1487-1490.

KANAMORI, H. (1977), The Energy Release in Great Earthquakes, J. Geophys. Res. 82, 2981-2987.

Kelleher, J., and SAvino, J. (1975), Distribution of Seismicity before Large Strike Slip and Thrust-type Earthquakes, J. Geophys. Res. 80, 260-271.

OKaDA, Y. (1985), Surface Deformation due to Shear and Tensile Faults in a Half-space, Bull. Seismol. Soc. Am. 75, 1135-1154. 
Pacheco, J. F., and Sykes, L. R. (1992), Seismic Moment Calalog of Large, Shallow Earthquakes, 1900-1989, Bull. Seismol. Soc. Am. 82, $1306-1349$.

Ruff, L. J., and Miller, A. D. (1994), Rupture Process of Large Earthquakes in the Northern Mexico Subduction Zone, Pure Appl. Geophys. 142, 101-172.

SCHWARTz, S. Y., and RUFF L. J. (1987), Asperity Distribution and Earthquake Occurrence in the Southern Kuril Islands Arc, Phys. Earth Planet. Inter. 49, 54-77.

Sipkin S. A. (1986), Estimation of Earthquake Source Parameters by the Inversion of Waveform Data: Global Seismicity, Bull. Seismol. Soc. Am. 76, 1515-1541.

TichelaAr, B. W., and RufF, L. J. (1993), Depth of Seismic Coupling along Subduction Zones, I. Geophys. Res. 98, 2017-2037.

YoshidA, Y., SATAKe, K., and ABE, K. (1992), The Large Normal-faulting Mariana Earthquake of April 15, 1990 in Uncoupled Subduction Zone, Geophys. Res. Lett. 19, 297-300.

(Received August 10, 1994; revised November 11, 1994; accepted January 3, 1995) 